\title{
Parenting Styles, Parental Involvement in School, and Educational Functioning of Children with Special Needs Integrated into Mainstream Education
}

\author{
Yosi Yaffe \\ Ohalo Academic College, Israel \\ E-mail:vabsolut@windowslive.com>
}

Received: August 15, 2015 Accepted: Nov. 26, 2015 Published: November 26, 2015

doi:10.5296/jse.v5i4.8588

URL: http://dx.doi.org/10.5296/jse.v5i4.8588

\begin{abstract}
The study examined the relationship between parenting style and parental involvement in school and educational functioning among children with various disabilities integrated into mainstream education. It includes 116 parents of children with special needs who reported their children according to formal educational evaluations they possessed. The sample of children reported by parents disproportionately represents six age layers $\mid \bar{X}=9.23$, $S D=1.85 \mid$ and 3 main disability groups. Multivariate regression analyses indicated that parenting style and parental involvement in school explain a significant proportion of the variance in educational functioning among children with attention deficit disorders and complex disabilities. Within the first group, parental involvement significantly mediated the relationship between parenting style and educational functioning. Parenting style and parental involvement modestly predicted academic achievements in language skills and mathematics field (respectively) in the general sample. Significant relationships between parenting style and educational functioning and achievements in these tests pointed to better performance of children of authoritative parents compared with children of authoritarian parents. The main findings stress the need to encourage and nurture authoritative parenting traits, along with consistent parental involvement in school, as significant means of improving and strengthening the educational functioning among children with special needs integrated into mainstream education.
\end{abstract}

The theoretical and educational implications of these findings are discussed in the light of relevant literature.

Keywords: parenting style, disabilities, functioning, achievements 


\section{Introduction}

The field of styles of parenting and child-raising has long enjoyed a central place in the theoretical and research discourse about child education and development. The importance of parental functioning in relation to the psychological development of children has been discussed in general, but has yet to be studied in depth in the context of special needs populations. The majority of the relevant research literature has focused on the implications of the child's disability for the parents and family members. The current study examines the connection between the parenting style and the parents' involvement in the school and the educational functioning of special needs children.

The study of parenting styles developed within a wide field dealing with the socialization processes taking place between parent and child. Theoreticians and researchers focused on different patterns of parental behavior that are relevant to parent-child relations that could predict and explain developmental and functional features among children. Two of the most fundamental parental components identified in this context are parental control (or demandingness) and parental acceptance (or responsiveness) (Darling \& Steinberg, 1993; Steinberg, 2001; Maccoby \& Martin, 1983). The typical expressions of the parental control element are setting boundaries and supervising the child's behavior while granting autonomy (Steinberg, Lamborn, Dornbusch \& Darling, 1992). Their negative expressions are exaggerated patterns of regulating the child's routine and activity, over-protectiveness, close training in how to think and feel, and so on-signs of psychological control (Barber, 1996; Schwarz, Barton-Henry \& Pruzinsky, 1985; Steinberg, Elmen \& Mounts, 1989). Parental acceptance is characterized by a combination of warmth and responsiveness, and is expressed in accepting the child's emotions, active listening, providing praise, and emotional and behavioral involvement in the child's life and activities (Maccoby, 1992).

On the basis of these findings, conceptualizations of generalized parenting styles have been developed (Baumrind, 1971; Maccoby \& Martin, 1983), denoting the types of parenting expressed in the positions and behaviors toward their children, and constituting a basis for the overall family atmosphere (for example: authoritative, authoritarian, and permissive parenting). The main features distinguishing these parenting types refer to the extent or degree to which the parent sets boundaries and provides guidance, explains and justifies demands and expectations, applies control and power, and provides emotional support (Yaffe, 2013). The authoritative parent, for instance, combines consistent discipline and the setting of boundaries (behavioral control) with the provision of emotional warmth and support, logic, and negotiation. Such parents recognize their duties and rights as adults and as the authority figures, but these things do not detract from the child's rights, unique qualities, and desire for independence (Baumrind, 1968, 1971, 1978). The Authoritarian parent, on the other hand, is characterized with high level of psychological control along with low degree of support and emotional availability.

Over the years, much evidence has accumulated linking patterns of authoritative parenting to optimal behavioral, social, and educational functioning among typically developing children (Dyches, Smith, Korth, Roper \& Madleco, 2012; Eisenberg et al., 2005; Spera, 2005; 
Steinberg, Elmen \& Mounts, 1989). Other studies have examined the specific mechanism explaining the link between parental features and successful educational functioning among children of authoritative parents. Ishak and colleagues (Ishak, Low \& Law, 2012), for instance, compared the relationship between self-concept and academic achievements among adolescents with authoritative parents and adolescents with authoritarian parents. They found that the general self-concept was related to academic achievements only among the children of authoritative parents, and that the strength of the connection between academic self-concept and achievements was significantly stronger in this group. The researchers attributed the differences to the promoting function of the authoritative parent, who tends to give warmth and respect and to accept the child's individuality, and to nurture the child's perception of high self-worth.

In another longitude study (Juany \& Silbereusen, 2002), the researchers identified parental practices that specifically related to positive academic functioning among adolescents. Beyond the variables related to the children, including their perceived and actual cognitive ability, they found that expressions of parental involvement in studies, parental academic aspirations for their children, and a context of warm parenting significantly predicted the children's actual achievements. Thus, for example, adolescents with a configuration of high cognitive ability and high perception of ability, along with warm and involved parents, presented the highest academic achievements. In contrast, children whose parents were not involved in their studies presented lower educational abilities, particularly when their cognitive skills were low. In fact, only high cognitive abilities were found in this study as a protective factor against uninvolved parenting in the context of academic achievements.

The interaction between parental involvement in the school and parenting style in relation to the children's academic achievements was best clarified in the study of Steinberg, Lamborn, Dornbusch and Darling (1992) which examined the effect of parenting practices on the educational functioning of normative children at school. This study found that the connection between authoritative parenting and academic achievements and other indices of academic functioning was mediated by the degree of parental involvement in the school. In other words, it found that children of authoritative parents function better educationally to a large extent due to their parents being more involved in their education in the school system. The study also showed that the connection between parental involvement in school and academic achievements was significantly moderated as the parents were less authoritative, and almost disappeared when the parents were not authoritative. The researchers concluded that non-authoritative parenting can significantly undermine the beneficial influence of parental involvement in the school, and vice versa. Two of these researchers (Darling \& Steinberg, 1993) later proposed the contextual model of parenting style to explain the advancing/moderating role of parenting style in the context of parental involvement in school and children's educational functioning. According to this model, parenting style should be viewed as a sort of family climate (context) in which parenting practices are applied and educational goals are stressed, and it can regulate the effectiveness and achievement of these goals. In this context, it appears that the way parents express and apply their involvement in the children's studies, and the way they encourage them (overall parenting style-support, 
consistency, monitoring, guidance) plays a decisive role in influencing the children's functioning.

While there has been extensive research regarding the importance of parenting quality in relation to the developmental variables of normal children, only little is known in this context regarding children with special needs. Although there are concrete reasons for examining separately the connection between parenting styles and outcome aspects among children with various disabilities (Dyches et al., 2012), several recent comprehensive reviews show that the extent of research in this field is very limited (e.g., Dyches et al., 2012; Hasting \& Beck, 2004; Raya, Ruiz-Olivares, Pino \& Hurruze, 2013). In fact, most of the literature on this issue has actually focused on the negative implications of raising children with various disabilities on the parents' functioning in the family and their mental state. In general, it appears that parents of children with various disabilities suffer from greater mental tension and are at higher risk of suffering psychiatric disorders and adopting non-adaptive parenting patterns (Deault, 2010; Gau \& Chang, 2013; Raya et al., 2013).

The relatively limited evidence relating parenting styles to the educational and behavioral functioning of children with developmental and emotional disabilities stress the dynamic and two-way nature of the parents' and children's characteristics. In general, it appears that authoritative parenting is more difficult to implement and less stable over time among children with various developmental disabilities. This is because in such cases the adoption of a parenting style relies more on the child's characteristics and not just on the parent's characteristics (Woolfson \& Grant, 2005). Most of the studies about children with ADHD, for example, show that the parents' characteristics moderate the influence of the children's characteristics on their development and adaptation to the various circles of life (Deault, 2010; Gau \& Chang, 2013; Healey, Flory, Miller \& Halperin, 2011; Kaiser, McBurnett \& Pfiffner, 2011; Modesto-Lowe, Danforth \& Brooks, 2008). Raising children with ADHD involves great mental stress and difficulty, which project onto the parental functioning and style, and this in turn is related to the children's functioning. Moreover, a study by Kaiser and colleagues (Kaiser et al., 2011), found that negative parental functioning was a unique predictor of low social skills and aggressive behavior among children with ADHD, independently of the severity of the disorder's symptoms.

Other studies show that parents of children with developmental disabilities tend to be less involved in their children's studies and to feel less competent in this context (Rogers, Wiener, Martton \& Tannocl, 2009), despite the great importance of this parental practice in relation to educational functioning having been demonstrated, although to a limited extent, even among children with special needs (Al-Shammari \& Yawkey, 2008).

Thus, while the literature in this field focuses on the negative family dynamics that develop in relation to the children's disabilities, less is known regarding the positive parenting features among these groups. In fact, most of the knowledge at our disposal regarding effective parenting patterns in relation to outcome variables among children results from theoretical frameworks and research knowledge bases about parents of typically developing children. Still, a few sources imply that when parents of children with special needs succeed in 
applying an authoritative-like parenting style when raising children with special needs, this is predicted to have noticeable positive implications for the children's functioning on the emotional, social, and educational levels. In general, among children with multi-problem developmental disabilities (Downs syndrome and autism), this parenting style was expressed in a high level of responsiveness, sensitivity, and training, and it was related to improved communicative and sociable functioning among these children (Dyches et al., 2012). Among children with attention deficit and learning disabilities, an identical positive parenting format was found to serve a moderating role regarding the connection between the disability's patterns and the social and emotional functioning of these children (Barkauskiene, 2009; Healey et al., 2011). Indeed, warm and supportive parenting served in these cases as a protective factor against the negative influences of the disability's features on the children's social adaptation and their tendency to develop internalized and externalized behavioral disabilities.

All this evidence seems promising regarding the importance of parental functioning in terms of the adaptation and advancement of children with special needs, despite the role played by their disability in the context of their overall functioning. The contribution of parenting style and the dynamic between it and positive parenting practices of parental involvement in the children's school education, in relation to the educational functioning and academic achievements among these groups, is clearly lacking and requires significant further research efforts (see: Deault, 2010). The present research focuses on these specific aspects in an attempt to broaden the research scope regarding parenting styles among groups with these special features.

In light of the literature review above, this study examines the following research questions:

1. Is there a connection between the parenting style of parents of children with special needs and the degree of their involvement in their children's education in integrated educational settings?

2. How is parenting style of parents of children with special needs associated with their children's academic and educational functioning in integrated educational settings?

3. What is the contribution of parental involvement in school in predicting the academic and educational functioning of children with special needs studying in integrated educational settings?

4. Does parenting style moderate the relationship between parental involvement in school and the academic and educational functioning of children with special needs studying in integrated educational settings?

\section{Method}

\section{Participants}

The study included 116 parents of children with special needs integrated into mainstream education, 80 of them women and 35 of them men (one parent's gender was not reported). The age of the parents was between 27 and 65, with an average of 41.10 and standard 
deviation of 6.89 . Ninety-six of them $(83 \%)$ were married, and the rest were single parents. Most of the parents in the sample (about 89\%) were born in Israel, and had an average education of 13.2 years $(\mathrm{SD}=2.9)$. The parents reported their children's original disability, in accordance with their official diagnosis, and also their academic condition, based on the school's official educational evaluations in their possession. The sample of the children reported by the parents represents non-proportionally six age groups $(\overline{\mathrm{X}}=9.23, \mathrm{SD}=1.85)$ and 3

main disability groups, according to the distribution detailed in Table 1. Since the age groups were not significantly different in the level of their academic and educational functioning examined in the study (the dependent variables), both in the total sample and in the disability group, all the statistical tests were conducted as one age group, without controlling for this variable.

Table 1. Distribution of children reported in the sample (by the parents) by disability and age group

\begin{tabular}{lcccc}
\hline & $\begin{array}{c}\text { Attention deficit } \\
\text { disorder }\end{array}$ & $\begin{array}{c}\text { Learning } \\
\text { disabilities (LD) }\end{array}$ & $\begin{array}{c}\text { Complex } \\
\text { disabilities }\end{array}$ & Total \\
\hline Grade 1-2 & 11 & 4 & 3 & 18 \\
Grade 3-4 & 25 & 12 & 7 & 44 \\
Grade 5-6 & 25 & 16 & 13 & 54 \\
Total & 61 & 32 & 23 & 116 \\
\hline
\end{tabular}

$52.6 \%$ of the children reported in the current sample were children with attention deficit disorder, $27.6 \%$ had learning disabilities, and the rest (19.8\%) represented a wider range of disabilities that were combined into one group (hereafter: the complex disabilities group). This group combines children with developmental disabilities (autism, light mental retardation) and sensory disabilities, due to their low numbers in the current sample.

\section{Measures}

Parenting styles. The overall parenting styles of the parents participating in the study were assessed using Buri's Parental Authority Questionnaire (PAQ: Buri, 1991), based on the parents' self-reporting. The questionnaire contains 30 items (10 items for each parenting style), and serves for classifying the parents into one of three parenting styles, according to Baumrind's concepts: authoritative (for example, "my parents always encouraged discussion whenever I felt the rules and restrictions in the family were unfair"), authoritarian (for instance, "even if the children did not agree with them, my parents emphasized that it was for our own good if they forced us to behave the way they thought right"), and permissive (for example, "when I was growing up, my parents felt that in a properly managed home the children should receive whatever they wanted in the family, to the same degree as the 
parents"). The response scale for each item is from 1 (do not agree at all) to 5 (agree strongly), and the total score range for each parenting scale was between 10 and 50, with the higher score representing a higher characterization of that parenting style. Each participant's parenting style classification was determined by the highest grade among the three scales. This is a valid instrument with relatively high internal reliability and retest reliability data (see: Buri, 1991; Smetana, 1995), which is accepted in Israel and around the world to measure the three parenting styles. The instrument in its present format received sufficient reliability data as internal consistency (alpha Cronbach) of .77 for each of the two parenting scales used in the current research (authoritative and authoritarian).

Parental involvement. To assess the degree of the parents' involvement in their children's educational setting and activities, we used the parental involvement in the educational setting questionnaire (Hodotov, 2001). This is an instrument based on a questionnaire developed in a study by Levy (1997; in Hodotov, 2001), adapted for special education in terms of the activities. The questionnaire includes 7 statements relating to three main areas: the child's area (for example, participating in constructing the child's educational-therapeutic program), the organization of the educational setting area (for example, participating in parents' committees), and the wider community area (for instance, participating in national committees). These three areas were empirically confirmed in Hodotov's study, using a factor analysis that produced three factors that explain about $78 \%$ of the variance of this variable. The responses of the participants are given on a four-level Lickert scale (never, sometimes, often, very often). The grade on the three areas is obtained from the average assessment of the items belonging to each area, so that the higher score indicates greater involvement. In the current study, reliability as internal consistency of .76 was obtained for this scale, which is sufficient considering the relatively small number of items composing it.

Academic/educational functioning. The assessment of the functioning of the children reported in the study by their parents was based on a structured questionnaire simulating the standard format of a primary school educational evaluation in terms of structure, subjects, and scales. The questionnaire was designated for parents reports, based on the school latest educational evaluation in their possession. Based on the standard subjects studied in primary school and the accepted parameters for assessing general functioning, three general assessment measures were created for this study: educational-social functioning (homework, behavior, bringing equipment, tidiness and organization, behavior to teachers and friends; mean $\mathrm{r}=.48, \mathrm{p}<.001$ ), language skills achievements (spelling, handwriting, reading; mean $\mathrm{r}=.68, \mathrm{p}<.001$ ), and mathematical subjects achievements (arithmetic, geometry; $\mathrm{r}=.81, \mathrm{p}<.001$ ). These were generated by calculating the average of all the individual grades (subjects or areas appearing in parentheses above) separately for each of the three general educational field, after ensuring that a significant positive correlation existed between them.

\section{Procedure}

The collecting of data was conducted as part of a research exercise in an academic course at an education college in the north of Israel. During the exercise, 56 students were requested to meet parents of children with any type of special needs who are integrated into mainstream 
education. Parents of children with special needs were selected individually by each student upon their early introduction or through acquaintance. To collect the data, the students met with the parents in their homes (not in the school), after approaching them personally in advance and receiving their consent and willingness to participate in the study. The parents were asked to fill in the required details and to answer the questionnaires described above, usually in the student's presence. The students were carefully and uniformly trained in the course on how to manage the contact with the parents and on the data collection procedure, but were requested to locate the parents independently. They were guided to inform the participants' parents in advance about all the information relevant to the current study, including its goals, the information requested, and its planned usage. The necessary means were also taken to ensure the privacy of the reporting participants (parents and children), by using anonymous questionnaires and not using any original documents belonging to the participants. This is why, for example, a questionnaire simulating a report card was provided, which the parents filled in based on the children's report cards. All the information requested, including information about the child's main difficulty (the official disability) was provided by the parents of their own free will. The parents were informed that they were entitled not to provide any information they did not wish to provide, and that they could retract their participation in the study. The data collected were transferred raw to the study's researchers, who supervised its input and conducted the statistical analyses required. Finally, the discussed procedure of data collection was ethically approved in advance by the head of the department of special education in the academic institution where the course took place.

\section{Results}

In order to study the general trends of connections between the study's central variables in the general sample, first we calculated the correlations between the parenting styles, the parental involvement in school, and the children's educational/academic functioning in school scales. Preliminary tests were also conducted regarding the effect of the demographic variables on the study's depended variables, and as necessary these were included or controlled in the analyses examining the study's research questions as described below.

An examination of the data in Table 2 shows that the parenting styles are negatively correlated with each other, and inversely related with the measures of the children's academic and educational functioning in school. The authoritative style is positively and significantly correlated with academic achievements in the areas of language, mathematics, and educational functioning among the children in the sample (in rising order), so that the more authoritative the parent's parenting style, the better the child functions in educational and academic terms. The authoritarian style, in contrast, is significantly connected with two of these measures, but in the negative direction. Finally, we can see that parental involvement in school is positively and significantly associated with educational functioning in the school and with achievements in mathematical subjects. Since there is a correlative overlap between this variable and the parenting styles, further investigation is required to determine the unique contribution of each of them to explaining the educational and academic functioning of the children in the study. 
Table 2. Correlation matrices (Pearson), averages, and standard deviations of the parental scales and the measures of educational functioning in the school in the general group $(\mathrm{N}=116)$

\begin{tabular}{|c|c|c|c|c|c|c|}
\hline Scale & 1 & 2 & 3 & 4 & 5 & 6 \\
\hline 1. Authoritative parenting style & - & $-.26 * *$ & $.36 * * *$ & $.33 * *$ & $.25^{*}$ & $.25^{* *}$ \\
\hline 2. Authoritarian parenting style & & - & $-.28 * *$ & $-.26 * *$ & $-.21 *$ & -.11 \\
\hline 3. Parental involvement in the school & & & - & $.29 * *$ & .18 & $.21 *$ \\
\hline 4. Educational functioning in the school & & & & - & $.52 * * *$ & $.47 * * *$ \\
\hline 5. Language skills achievements & & & & & - & $.57 * * *$ \\
\hline 6. Mathematical skills achievements & & & & & & - \\
\hline Mean & 36.68 & 29.46 & 2.48 & 3.51 & 2.86 & 3.22 \\
\hline Standard deviation & 5.80 & 6.50 & .65 & .90 & 1.07 & .95 \\
\hline
\end{tabular}

$* p<.05, * * p<.01, * * * p<.001$

The association between parenting style and parental involvement in the school among parents of children with special needs

Table 2 shows that the authoritative and authoritarian scales are inversely correlated with parental involvement in the school among the general group: the authoritative style has a positive and very significant correlation with the variable of parental involvement $(\mathrm{r}=.36$, $\mathrm{p}<.001)$, while the authoritarian style is negatively correlated with this variable $(\mathrm{r}=-.28$, $\mathrm{p}<.01$ ). This means in general, that parents of children with special needs with different styles are differentially involved in the education of their children in mainstream education. Accordingly, authoritative parenting is related to increased levels of parental involvement in school.

These trends in the general group were also tested among each specific disability group, according to the division described in the methods section. From examining the correlations in the group of children with learning disabilities $(n=32)$, a positive correlation of significant force was obtained between the authoritative parenting and parental involvement in the school $(\mathrm{r}=.62, \mathrm{p}<.001)$. In the group of children with attention deficit disorder $(\mathrm{n}=61)$, a weaker correlation was recorded between these variables $(\mathrm{r}=.34, \mathrm{p}<.01)$, and a negative correlation appeared between authoritarian parenting and parental involvement $(\mathrm{r}=-.27$, 
$\mathrm{p}<.05)$. In the complex disabilities group $(\mathrm{n}=22)$ no significant correlations between the variables were found, although a negative correlation was obtained between the authoritarian scale and parental involvement $(\mathrm{r}=-.36, \mathrm{p}<.10)$, whose magnitude may be more significant in a larger sample.

The association between parenting style and parental involvement in the school and the academic and educational functioning of children with special needs

First, the participants who answered the Parental Authority Questionnaire (PAQ) were classified into the authoritative parents group $(n=90)$ and the authoritarian parents group $(n=26)$, in accordance with the instrument's classification instructions (see the instruments item in the method section). Participants classified as having a permissive parenting style $(n=3)$ were preliminary dropped from the original sample, due to their low number. The parent's gender was found to have a significant effect on two of the explained variables discussed in this section, but in light of sample size constraints in the sub-groups (parent's gender and disability type), the analyses examining the relevant research questions were based on the general parents' group, without distinguishing the participants' gender. This issue will be discussed in the limitations of the study section.

In order to examine the unique connection between parenting style and the variables of academic and educational functioning of the children at school, and to examine the additional contribution of parental involvement in the school to predicting these variables, three separate multivariate regression analyses were performed (Table 3). In the first two analyses, the predictors were inserted in two hierarchical steps: first we inserted into the equation the parenting style (categorical-dichotomous variable), and in the second step the variable of parental involvement in the school was inserted. The results of analysis 1 show that parenting style and parental involvement in school are significantly related to the level of educational functioning of integrated children with special needs, and together they explain about $17.4 \%$ of the variance in the grades of this variable among the children in the sample $(\mathrm{F}(2,103)=$ $10.88, \mathrm{p}<.001)$. The negative and significant $\beta$ value calculated for the variable of parenting style expresses, in this case, the fact that children with special needs who have authoritative parents function better in educational terms than children with authoritarian parents. The additional contribution of parental involvement, above and beyond parenting style, to the explained variance of educational functioning, was significant, and amounted to $4.3 \%$ (F (1, $103)=5.32, \mathrm{p}<.05)$. Furthermore, the Sobel test to examine the significance of the change in the regression coefficient of the parenting style variable following the insertion of parental involvement in school into the equation found that the latter variable partially mediates the relationship between parenting style and the educational-social functioning in the general sample $(\mathrm{Z}=2.58, \mathrm{p}<.001)$. This takes into consideration the significant correlations existing between all the variables involved in the regression equation (see Tables 2 and 3). This means that children with special needs who have authoritative parents function better in mainstream education from an educational-social point of view partly due to their parents being more involved in their education at school. 
Since we identified an effect of the disability group on the current explained variable (the level of the educational functioning of the attention deficit disorder group was significantly lower compared with that of the complex disabilities group) $(F(2,104)=4.72, p<.05)$, these trends were also tested in each disability group separately. Subject to the limitations of the sample size in each separate disability group, these general trends were found in the group of children with attention deficit disorder $(\mathrm{R}=22.7 \%$; $\mathrm{F}(2,52)=7.65, \mathrm{p}<.005)$ and in the group of children with complex disabilities $(\mathrm{R}=30.1 \%$; $\mathrm{F}(2,18)=3.88, \mathrm{p}<.05)$, but not in the group of children with learning disabilities. within the attention deficit disorder group, the parental involvement variable explained about $7.2 \%$ of the variance in the grades of the children's educational functioning $(\mathrm{F}(2,104)=4.72, \mathrm{p}<.05)$, while Sobel test indicates that its mediating effect on the relationship between parenting style and educational-social functioning was significant $(Z=1.96, \mathrm{p}<.05)$. In the complex disabilities group, the unique contribution of this variable to explaining the variance in educational functioning was not significant, but at the same time, the general regression in this case explains a larger proportion of this variance compared to the other groups, with parenting style having a greater unique weight in it.

Table 3. Summary of regression analyses for predicting the educational and academic functioning in the general sample by parenting style, parental involvement in school and the interaction between them

\begin{tabular}{lrrrr}
\hline Predictors & $\mathrm{B}$ & $\mathrm{S} . \mathrm{E}$. & $\mathrm{t}$ & \multicolumn{1}{c}{$p$} \\
\hline Analysis 1: Predicting educational-social functioning by parenting & & & & \\
style and parental involvement & & & & \\
Parenting style & -.66 & .19 & -3.40 & .001 \\
Parental involvement in the school & .29 & .23 & 2.31 & .023 \\
Parenting style * parental involvement & -.001 & .33 & -.004 & .996 \\
$\mathrm{R}^{2}$ & & 0.174 & \\
Analysis 2: Predicting achievements in language skills by parenting & & & & \\
style and parental involvement & & & & \\
Parenting style & -.55 & .24 & -2.27 & .025 \\
Parental involvement in the school & .21 & .16 & 1.30 & .196 \\
Parenting style * parental involvement & .29 & .42 & .69 & .493 \\
$\mathrm{R}^{2}$ & & 0.079 & \\
Analysis 3: Predicting achievements in mathematical subjects by & & & & \\
parental involvement, parenting style and their interaction & & & & \\
Parenting style & -.01 & .26 & -.06 & .955 \\
Parental involvement in the school & .31 & .14 & 2.17 & .032 \\
Parenting style * parental involvement & .70 & .38 & 1.87 & .064 \\
$\mathrm{R}^{2}$ & & 0.079 & \\
\hline
\end{tabular}

Note: The interaction data in analyses 1 and 2 were collected in separate regression analyses 
Regarding the achievements in language skills in the general sample (analysis 2), the predictive ability of the parenting variables was no more than $8 \%$ of the variance in the grades of this variable $(\mathrm{F}(2,101)=4.32, \mathrm{p}<.05)$, but in the current case, the unique contribution of parental involvement in school to this explained variance was not significant. Regarding parenting styles, we can see that there are differences between the children of authoritative parents and the children of authoritarian parents in the sample, in favor of the former, in achievements in language skills subjects.

Analysis 3 examined the contribution of the parental involvement in school and parenting style to explaining the variance in the achievement grades in the mathematical subjects, while accounting for the contribution of the interaction between these two predictors (whose significance will be discussed in the following section, in the context of moderation). The results of this analysis show that among the individual predictors in this context, only parental involvement has a significant contribution to explaining the variance of the children's grades in mathematical subjects. The overall weight of the regressive prediction for explaining the variance in academic achievements is relatively moderate in this case, and amounts to $7.9 \%(\mathrm{~F}(3,102)=2.93, \mathrm{p}<.05)$.

Parenting style as a moderator of the association between parental involvement in school and the academic and educational functioning of children with special needs

Examining the moderating effect of parenting style on the association between parental involvement and educational and academic functioning in school is based on a standard regression model using the Ordinary Least Squares system to test the significance of the interaction between the predictors as explaining the variance in the three educational measures tested in this study (for an extensive review, see: Hayes \& Hattehs, 2009). Table 3 presents the results of the interaction between the predictors according to the separate regression analyses beyond analyses 1 and 2 (The interaction in this two analyses has no influence on the general prediction lines but on the significance of the individual predictors, so the original regressions' data, with two predictors only, are reported). In analysis 3 , in contrast, a unified regression test was conducted in which the three predictors (involvement in the school, parenting style, and their interaction) were included simultaneously, due to the contribution of the interaction in this case to explaining the variance in the grades of achievements in mathematical subjects.

The results in this context show one notable finding, constituting partial evidence of the moderating role of parenting style in the context of achievements in mathematical subjects (see Table 3). It was found that the contribution of the interaction between the primary predictor (parental involvement) and parenting style to explain the variance of the achievements in mathematical subjects was significant at a $10 \%$ significance level $(\mathrm{t}=1.87$, $\mathrm{p}<.10$ ). This means that the parenting style moderates the association between these variables, so that in conditions of authoritarian parenting parental involvement significantly predicts the achievement grades in the mathematical subjects $(b=.86 ; t=2.51, p<.05)$, but this does not occur in conditions of authoritative parenting style. 
Finally, no evidence was found of a moderation for parenting style in the rest of the cases, while the interaction effect between the parental variables on the other two depended variables (educational functioning and achievements in language skills) was not significant.

\section{Discussion}

The current study deals with the connection between parenting styles, parental involvement in the school, and educational-academic functioning among three main groups of children with special needs integrated into the mainstream education system. In general, the current study partially reconstructs previous empirical findings in these contexts, from studies conducted upon typically developing children, and expands their validity to children with special developmental features. Regarding the first research question discussed in this study, the authoritative parenting style and the authoritarian parenting style were found to have a significant positive and a negative association (respectively) with the degree of parental involvement in school in the general group of the sample. This basic finding, originating in the group of parents of children with learning disabilities and attention deficit disorder (in descending order in terms of correlational strength), is consistent with previous research regarding parents of typically developing children (Paulson, 1994; Steinberg et al., 1992), indicating identical parental features existing in the context of involvement in school among authoritative parents of children with special needs. The differential tendencies of involvement in the child's education at school between authoritative and authoritarian parents can partially explain the findings discussed later, regarding the differences between these groups in terms of the children's educational and academic functioning.

The study's central research questions discussed the association between the parenting style and the outcome variables of academic and educational functioning among children with special needs in mainstream education. Special attention was paid in this context to examining the unique contribution of parental involvement in the school to explaining these outcome variables and understanding its role within the connection between parenting styles and the children's functioning at school. A series of regression analyses to predict the educational-social functioning and academic achievements in the linguistic and mathematical areas in school among the children in the sample led to a series of interesting and important results. Regarding the general sample, parenting style and parental involvement were found to predict about $17 \%$ of the variance in the grades for the children's educational-social functioning, of which the unique weight of the latter variable was significant (about $4 \%$ of the explained variance). These analyses show that children with special needs who have authoritative parents function better at school in educational terms compared with those with authoritarian parents. This finding constitutes further evidence of the advantage of authoritative parenting in relation to the children's adaptation and functioning, consistent with a long series of previous relevant findings in this area, showing the positive implications of authoritative parenting on children's development (Dyches, Smith, Korth, Roper \& Mandleco, 2012; Eisenberg et al., 2005; Ishak et al., 2012; Spera, 2005; Steinberg et al., 1989; Steinberg et al., 1992; Steinberg, 2001). While the present finding does not rule out the possibility of the inverse connection (positive functioning of children encourages authoritative parenting among parents), its importance is in advancing our understanding of 
the connection between these variables among children with special developmental features, regarding which the research literature has been lacking (Deault, 2010).

With regard to parental involvement in the school, beyond its unique contribution to explaining the variance in the educational functioning of the children in the sample, this variable was also found to significantly mediate the association between parenting style and educational functioning in the general sample and in the group of children with attention deficit disorder. From this we may conclude that children with special educational needs who have authoritative parents, particularly children with attention deficit disorder, function better in educational-social terms partially thanks to their parents' being more involved in their school education. This supports the conclusions of Steinberg and colleagues (Steinberg et al., 1992) regarding the mediating role of parental involvement also for children with special developmental features. The contextual model (Darling \& Steinberg, 1993) interprets this mediation path of parenting style in outcome contexts among children as resulting from the authoritative parenting tending to set specific goals regarding the children's school studies (optimal educational functioning), which are translated into educational practices (parental involvement in the children's studies), and these in turn advance the children's academic functioning and lead them to achievements.

An examination of these general trends in the three disability groups shows a higher rate of predicting the variance explained by parenting style and parental involvement exists in the attention deficit disorder group (significantly explained about $23 \%$ and $7 \%$, respectively, of the variance in the children's educational functioning), and only parenting style in the complex disabilities group (explained about 30\% of the variance in the children's functioning). In the latter group, parental involvement in school did not make a significant contribution to explaining the children's educational functioning. If we add to this the fact that in the learning disabilities group these parental variables did not significantly predict the variance in the educational-social functioning of the children, this sharpens the differences in the importance of the different parental variables as a function of the unique features and needs of children in each disability group. From this we may hypothesize that parenting practices, positive and negative, can have a differential impact on children with different developmental features. This hypothesis is supported by studies that identified a different effect of parental socialization in the context of the children's features, such as their temperament, gender, and developmental status (see: Bates, Dodge, Petit \& Ridge, 1998; Park, Belsky, Putnam \& Crnic, 1997; Rothbaum \& Weisz, 1994), but requires separate and in-depth clarification in the context of children with disabilities.

The fact that the parental variables studied in this research were not related to educational-social functioning among children with learning disabilities strengthens, though indirectly, its being distinguished from adjacent disability areas such as attention deficit disorder, and implies that in the case of children with learning disabilities the more relevant parenting practices were not taken into consideration. Further studies in this context will be required to test a wider range of parental variables among a homogeneous group of children with learning disabilities. Moreover, the inability of parenting styles and parental involvement to predict the educational functioning of children with learning disabilities in the 
current study could result from the fact that this is a disorder with very large phenomenological variance, requiring distinguishing between its sub-groups when testing the factors related to functional aspects among children belonging to this group. This assumption accords with the results of Barkauskiene's study (Bakauskiene, 2009), which identified differences in emotional adaptation between various groups of children with learning disabilities who had parents with a negative parenting style. In her study, negative parenting, characterized by excessive maternal control and negative affect, was related to internalized symptoms only among children with multiple learning disabilities.

Examining the connection between parenting style and parental involvement and specific academic achievements in school among all the children in the sample (in the absence of differences between the disability groups in terms of academic achievements, the regression analyses were calculated for the entire sample) revealed a differential and more modest contribution of the parental variables in these cases. Thus, parenting style significantly explained most of the variance in the linguistic skills grades by the parental variables, while only parental involvement in school significantly explained the variance in the academic achievement grades in mathematical subjects. In the latter case, parenting style had no unique contribution to explaining the variance, but this variable was found to play a surprising moderating role in the relation between parental involvement and academic achievements in the general sample (interaction effect between the predictors was significant for $p<.10$ ). In this context, we found that parental involvement in school was significantly connected to mathematical achievements, but only among children with special needs whose parents were authoritarian. While this finding supports the assumption of the moderating role of parenting style in general, it essentially contradicts the rationale regarding the protective and beneficial effect of the authoritative parenting style, in contrast with that of the authoritarian parenting style, derives from several works who dealt with the relationship between parenting practices and children's well-being (e.g., Barkauskiene, 2009; Blondal \& Adalbjamardottir, 2009; Healey et al., 2011; Steinberg et al., 1992; Yaffe \& Burg, 2013). This finding has yet to be reported in this specific form in the research literature, although there is some empirical evidence indicating the possibility that authoritarian parenting may be related to several aspects of successful academic functioning among children (Gonzalez, Greenwood \& Hsu, 2001; Kazmi, Sajjid \& Pervez, 2011), and even in the context of mathematical studies (Gonzalez \& Walters, 2006). Reviewing the research on this issue shows that most of the empirical evidence originates with typically developing children, while the dynamics between parental variables and academic functioning of children with special educational needs requires much further examination beyond the findings of the current study.

The weakened ability of the parental variables examined to predict specific academic achievements may indicate their generality in relation to children with fundamental functional-academic difficulties. Thus, consistent parental assistance in doing homework as a central aspect of parental involvement related to academic achievements among typically developing children (Spera, 2005) was not taken into account in the observational definition of parental involvement in the current research. Perhaps the adaptation of the scale to make it suitable for special education missed a series of aspects of parental involvement that are 
relevant to the functioning of children with special needs integrated into mainstream education. Other specific parenting practices that are relevant to the academic field, such as monitoring and setting academic goals, which have been found to predict specific academic achievements among normally developing children (Muller, 1993; Wigfield, 1993), may fill in the gap regarding the findings discussed in this paragraph. They may also throw additional light on the array of family variables that explain academic functioning at school among children with special educational needs.

The current study contributes to bridging the gap existing in the research literature about the socialization of children between typically developing children and children with developmental disabilities characterized by special educational needs. By joining the limited number of studies in this area, this study's importance is in following several generic parental variables that have been shown to be important in educating typically developing children, while examining them in the context of different children's development. The rationale that led to examining the importance of parental functioning in the context of the educational functioning of children with special needs receives significant support here and sets a challenge for further specific research among larger groups of children with homogeneous developmental features. The main findings stress the need to encourage and nurture authoritative parenting traits, along with consistent parental involvement in school, as significant means of improving and strengthening the educational-behavioral and even academic functioning among children with special needs integrated into mainstream education. However, the dynamics of parenting style along with specific educational practices within the family, in connection with the different functions of children with special needs may be distinguished among the sub-groups of this category, as a function of their unique features.

The current study is limited from a few methodological aspects. First and foremost, due to an error in data collection, the children's gender was not taken into consideration. This is an attribution variable that might differentiate the findings reported here in accordance with the children's gender, and in this respect its absence directly detracts from the external validity of the study's findings. Another limitation is related to the gender of the reporting parent, which was taken into account only partially in the current study due to the minority of the sample size in the various sub-groups. Given the gender differences known in the literature in terms of the dominant parenting styles, it is worth examining the research questions discussed here with a complete distinguishing between these groups. Finally, due to various considerations, the data of the current study regarding the parents' variables relied only on the reporting of one informant, the parent. It is obvious that varying the reporting sources could improve the methodological credibility of the data and strengthen the validity of the findings. Many researchers attribute great importance, in this context, to the children's perception of their parents' characteristics (e.g., Barber, 1996; Steinberg, 2001), and even stress its importance in relation to developmental and adaptation variables. The study's main conclusions should, of course, take this restriction into account. 


\section{Acknowledgement}

Dr. Yosi Yaffe (PhD.) holds a regular position as a lecturer and researcher at Ohalo Academic College in the department of special education. He also teaches and serve as thesis instructor of graduate students at Gordon College (both institutes are educational colleges), and at the open university of Israel

\section{References}

Al-Shammari, Z. \& Yawkey, T.D. (2008). Extent of Parental Involvement in Improving the Students' Levels in Special Education Programs in Kuwait. Journal of Instructional Psychology, 35(2), 140-150.

Barber, B.K. (1996). Parent psychological control: revisiting neglected construct. Child Development, 67, 3296-3319.

Barkauskiene, R. (2009). The Role of Parenting for the Adjustment of Children With and Without Learning Disabilities: A Person-Oriented Approach. Learning Disabilities: A Contemporary Journal, 7(2), 1-17.

Bates, J. E., Dodge, K. A., Pettit, G. S., and Ridge, B. (1998). Interaction of Temperamental resistance to control and restrictive parenting in the development of externalizing behavior. Developmental Psychology, 34, 982-985. http://dx.doi.org/10.1037/0012-1649.34.5.982

Baumrind, D. (1971). Current patterns of parental authority. Developmental Psychology Monographs, 4(1), 1-103. http://dx.doi.org/10.1037/h0030372

Baumrind, D. (1968). Authoritarian vs. authoritative Parental control. Adolescence, 3(11), 255-272.

Baumrind, D. (1978). Parental disciplinary patterns social competence in children. Youth \& Society, 9(3), 239-276. doi: 10.1177/0044118X7800900302

Blondal, K.S. \& Adalbjamardottir, S. (2009). Parenting Practices and School Dropout: A Longitudinal Study. Family Therapy, 36(3), 125-145. http://dx.doi.org/10.1111/jomf.12125

Buri, J.R. (1991). Parental Authority Questionnaire. Journal of Personality Assessment, 57(1), 110-119. http://dx.doi.org/10.1207/s15327752jpa5701_13

Darling, N. \& Steinberg, L. (1993). Parenting style as context: an integrative model. Psychological Bulletin, 113(3), 487-496. http://dx.doi.org/10.1037/0033-2909.113.3.487

Deault, L.C. (2010). A Systematic Review of Parenting in Relation to the Development of Comorbidities and Functional Impairments in Children with Attention-Deficit/Hyperactivity Disorder (ADHD). Child Psychiatry Human Development, 41, 168-192. http://dx.doi.org/10.1007/s10578-009-0159-4

Dyches, T.T., Smith T.B., Korth, B.B., Roper, S.O., \& Mandleco, B. (2012). Positive parenting of children with developmental disabilities: A meta-analysis. Research in Developmental Disabilities 33, 2213-2220. http://dx.doi.org/10.1016/j.ridd.2012.06.015 
Eisenberg, N., Zhou, Q., Spinrad, T.L., Valiente, C., Fabes, R.A., \& Liew, J. (2005).

Externalizing Problems: A Three-Wave Longitudinal Study. Child Development, 76(5), 1055 - 1071. http://dx.doi.org/10.1111/j.1467-8624.2005.00897.x

Gau, S.S. \& Chang, J.P. (2013). Maternal parenting styles and mother-child relationship among adolescents with and without persistent attention-deficit/hyperactivity disorder. Research in Developmental Disabilities, 34, 1581-1594. http://dx.doi.org/10.1016/j.ridd.2013.02.002

Gonzalez, A., Greenwood, G., \& Hsu, J. (2001). Undergraduate students' goal Orientations and their relationship to perceived parenting styles. College Student Journal, 35(2), 182-192.

Gonzalez, A. \& Wolters, C.A. (2006). The Relation between Perceived Parenting Practices and Achievements Motivations in Mathematics. Journal of Research in Childhood Education, 21(2), 203-217. http://dx.doi.org/10.1080/02568540609594589

Hastings, R. \& Beck, A. (2004). Practitioner review: stress intervention for parents of Children with intellectual disabilities. Journal of Child Psychology and Psychiatry, 45, 1338-1349. http://dx.doi.org/10.1111/j.1469-7610.2004.00357.x

Hayes, A.F. \& Hattehs, J. (2009). Computational procedures for probing interactions in OLS and logistic regression: SPSS and SAS implementations. Behavior Research Methods, 41(3), 924-936. http://dx.doi.org/10.3758/brm.41.3.924

Healey, D.M., Flory, J.D., Miller, C.J., \& Halperin, J.M. (2011). Maternal Positive Parenting Style is Associated with Better Functioning in Hyperactive/Inattentive Preschool Children. Infant and Child Development, 20, 148-161. http://dx.doi.org/10.1002/icd.682

Ishak, Z., Low, S.F., \& Lau, P.L. (2012). Parenting Style as a Moderator for Students' Academic Achievement. Journal of Science Educational Technology, 21, 487-493. http://dx.doi.org/10.1007/s10956-011-9340-1

Juang, L.P. \& Silbereisen, R.K. (2002). The Relationship between Adolescent Academic Capability Beliefs, Parenting and School Grades. Journal of Adolescence, 25, 3-18. http://dx.doi.org/10.1006/jado.2001.0445

Kaiser, N.M., McBurnett, K. \& Pfiffner, L.J. (2011). Child ADHD Severity and Positive and Negative Parenting as Predictors of Child Social Functioning: Evaluation of Three Theoretical Models. Journal of Attention Disorders, 15(3), 193-203. http://dx.doi.org/10.1177/1087054709356171

Kazmi, S.F., Sajjid, M. \& Pervez, T. (2011). Parental Style and Academic Achievement among the Students. International Journal of Academic Research, 3(2), 582-588.

Maccoby, E. E. (1992). The role of parents in the socialization of children: An historical overview. Developmental Psychology, 28, 1006-1017. http://dx.doi.org/10.1037//0012-1649.28.6.1006 
Maccoby, E. E., \& Martin, J. A. (1983). Socialization in the context of the family: Parent-child interaction. In P. H. Mussen (Series Ed.) \& E. M. Hetherington (Vol. Ed.), Handbook of child psychology, 4. Socialization, personality, and social development (pp. 1-101). New York: Wiley.

Modest-Lowe, V. Danforth, J. S., \& Brooks, D. (2008). ADHD: Does Parenting Style Matter? Clinical Pediatrics, 47(9), 865-872. http://dx.doi.org/10.1177/0009922808319963

Muller, C. (1993). Parental involvement and academic achievement: An analysis of Family resources available to the child. In Schneider, B., and Coleman, J. S. (eds.), Parents, Their Children, and Schools, Westview, Boulder, CO, pp. 73-113.

Park, S.-Y., Belsky, J., Putnam, S., \& Crnic, K. (1997). Infant emotionality, parenting, and three-year inhibition: Exploring stability and lawful discontinuity in a male sample. Developmental Psychology, 33, 218-227. http://dx.doi.org/10.1037/0012-1649.33.2.218

Paulson, S. E., Marchant, G. J., \& Rothilsberg, B. A. (1998). Early adolescents' perceptions of patterns of parenting, teaching, and school atmosphere: Implications for achievement. Journal of Adolescents, 18, 5-26. http://dx.doi.org/10.1177/0272431698018001001

Raya, A.F., Ruiz-Olivares, R, Pino, M.J., \& Herruzo, J. (2013). Review about Parenting Style and Parenting Practices and Their Consequences in Disabled and Non-Disabled Children. International Journal of Higher Education, 2(4), 205-213. http://dx.doi.org/10.5430/ijhe.v2n4p205

Rogers, M.A.,Wiener, J., Marton, I., \& Tannock, R. (2009). Parental involvement in children's learning: Comparing parents of children with and without Attention-Deficit/Hyperactivity Disorder (ADHD). Journal of School Psychology, 47, 167-185. http://dx.doi.org/10.1016/j.jsp.2009.02.001

Rothbaum, F., \& Weisz, J. R. (1994). Parental caregiving and child externalizing behavior in nonclinical samples: A meta-analysis. Psychological Bulletin, 116, 55-74. http://dx.doi.org/10.1037//0033-2909.116.1.55

Schwartz, J.C., Barton-Henry, M.L., \& Pruzinsky, T. (1985). Assessing child-rearing behaviors: A comparison of rating made by mother, father, child, and sibling on the CRPBI. Child Development, 56, 462-479. http://dx.doi.org/10.2307/1129734

Spera, C. (2005). A Review of the Relationship Among Parenting Practices, Parenting Styles, and Adolescent School Achievement. Educational Psychology Review, 17(2), 125-145.

Steinberg, L. (2001). We know something: parent-adolescent relationships in retrospect and prospect. Journal of research on Adolescence, 11(1), 1-19. http://dx.doi.org/10.1007/s10648-005-3950-1

Steinberg, L., Elmen, D.J., \& Mounts, N.S. (1989). Authoritative parenting, psychosocial maturity and academic success among adolescents. Child Development, 60, 1424-1436. http://dx.doi.org/10.2307/1130932 


\section{Macrothink}

Steinberg, L., Lamborn, S.D., Dornbusch, S.M., \& Darling, N. (1992). Impact of Parenting practices on adolescent achievement: Authoritative Parenting' school involvement and encouragement to succeed. Child Development, 63, 1266-1281. http://dx.doi.org/10.1111/j.1467-8624.1992.tb01694.x

Wigfield, A. (1993). Why should I learn this? Adolescents' achievement values for different activities. Adv. Motivat. Achiev., 8, 99-138.

Woolfson, L. \& Grant, E. (2006). Authoritative parenting and parental stress in parents of pre-school and older children with developmental disabilities. Child: Care, Health \& Development, 32(2), 177-184. http://dx.doi.org/10.1111/j.1365-2214.2006.00603.x

Yaffe, Y. (2013). "Parental authority": What do We Know about the Construct? International Journal of Educational Research and Development, 2(9), 211-219.

Yaffe, Y. \& Burg, D. (2014). Corporal Punishment as a Parental Practice and Anxiety in Preadolescent Children. Journal of Social Science Studies, 2(1), 13-31. http://dx.doi.org/10.5296/jsss.v1i2.5099 